\title{
HIGHLIGHTS
}

PROSTATE CANCER

\section{New insight into mechanisms of castration resistance}

Constitutively active androgen receptor splice variants (ARVs) have been implicated in the progression of prostate cancer to a castration-resistant state. Two new papers add to our understanding of how this might occur, highlighting the involvement of full-length androgen receptor (AR).

In the first study, Sun et al. report isolation of a novel splice variant $\mathrm{AR}^{\mathrm{v} 567 \mathrm{es}}$, so-called because it lacks exons 5, 6 and 7, which encode the ligand-binding domain. As expected, $\mathrm{AR}^{\mathrm{v} 567 \mathrm{es}}$ was found to be constitutively active and the researchers turned their attention to its role in castration-resistant prostate cancer (CRPC). They detected $\mathrm{AR}^{\mathrm{v} 567 \mathrm{es}}$ expression in over $50 \%$ of prostate cancer specimens taken from men who had received androgen deprivation therapy and subsequently died from their disease, with particular abundance in tumors exhibiting the lowest levels of androgen. A role in disease progression was confirmed in xenograft experiments, where human cells expressing $\mathrm{AR}^{\mathrm{v} 567 \mathrm{es}}$ were capable of forming castration-resistant tumors in immunocompromised mice.

Until now, it was believed that constitutively active ARVs signal independently of the full-length receptor, but here investigators report a previously unknown physical interaction between the two. Binding of $\mathrm{AR}^{\mathrm{v} 567 \mathrm{es}}$ to full-length receptor was found to trigger ligandindependent nuclear translocation and enhanced transcriptional activity of the $\mathrm{AR}$, resulting in cell proliferation despite low androgen concentrations. These data suggest that splice variants can signal in two ways-with or without full-length AR.

Watson and colleagues have gone a step further in their research, suggesting that the full-length receptor is an absolute requirement for ARV-driven castration resistance. Their work is based on another constitutively active splice variant, AR-V7, which is associated with poor prognosis if detected early in a patient's disease course.

MDV3100 is a promising antiandrogen-currently in a phase III trial for CRPC-which exerts its effects by blocking the AR ligandbinding domain. Watson and his team hypothesized that because AR-V7 lacks the ligand-binding domain, its activity would be unaffected by MDV3100, and as a result patients whose tumors express

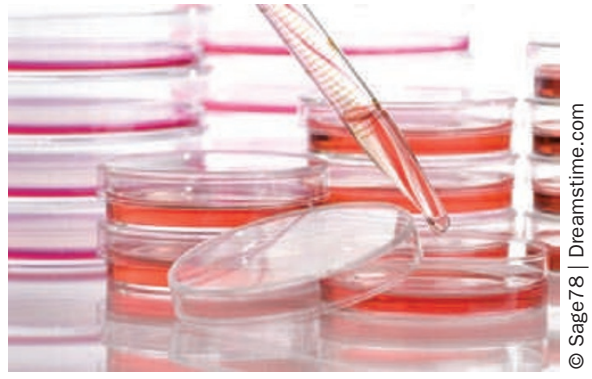

this splice variant might be refractory to MDV3100 treatment. To their surprise, Watson et al. found that MDV 3100 was able to block the growth of AR-V7-induced tumors in a castrationresistant LNCaP xenograft model. Use of small interfering RNA revealed that full-length AR was responsible for mediating the effects of AR-V7 on disease progression. The authors agree that heterodimerization between ARVs and full-length receptor, such as that observed by Sun et al., is the most likely mechanism of interaction.

\section{Sarah Payton}

Original articles Sun, S. et al. Castration resistance in human prostate cancer is conferred by a frequently occurring androgen receptor splice variant. J. Clin. Invest. 120, 2715-2730 (2010) | Watson, P. A. et al. Constitutively active androgen receptor splice variants expressed in castration-resistant prostate cancer require full-length androgen receptor. Proc. Natl Acad. Sci. USA 107, 16759-16765 (2010) 